\title{
Management of ulcerative colitis in Taiwan: consensus guideline of the Taiwan Society of Inflammatory Bowel Disease
}

\author{
Shu-Chen Wei ${ }^{1}$, Ting-An Chang ${ }^{2}$, Te-Hsin Chao ${ }^{3}$, Jinn-Shiun Chen ${ }^{4}$, Jen-Wei Chou ${ }^{5}$, Yenn-Hwei Chou ${ }^{6}$, \\ Chiao-Hsiung Chuang ${ }^{7}$, Wen-Hung Hsu ${ }^{8}$, Tien-Yu Huang ${ }^{9}$, Tzu-Chi Hsu ${ }^{10}$, Chun-Chi Lin ${ }^{11}$, Hung-Hsin \\ $\operatorname{Lin}^{11,12}$, Jen-Kou Lin ${ }^{11}$, Wei-Chen Lin ${ }^{13}$, Yen-Hsuan Ni ${ }^{14}$, Ming-Jium Shieh ${ }^{15}$, I-Lun Shih ${ }^{16}$, Chia-Tung Shun ${ }^{17}$, \\ Yuk-Ming Tsang $^{18}$, Cheng-Yi Wang ${ }^{1}$, Horng-Yuan Wang ${ }^{19,20,21}$, Meng-Tzu Weng ${ }^{22}$, Deng-Chyang Wu ${ }^{23,24}$, \\ Wen-Chieh $\mathrm{Wu}^{25}$, Hsu-Heng Yen ${ }^{26}$, Jau-Min Wong ${ }^{1}$ \\ ${ }^{1}$ Department of Internal Medicine, National Taiwan University Hospital, National Taiwan University College of Medicine, Taipei, ${ }^{2}$ Department \\ of Pathology, Taipei City Hospital Renai Branch, Taipei, ${ }^{3}$ Division of Colorectal Surgery, Department of Surgery, Taichung Veterans General \\ Hospital, Taichung, ${ }^{4}$ Division of Colorectal Surgery, Chang Gung Memorial Hospital at Linkou, Taoyuan, ${ }^{5}$ Division of Gastroenterology and \\ Hepatology, Department of Internal Medicine, China Medical University Hospital, Taichung, ${ }^{6}$ Division of General Surgery, Department of \\ Surgery, Shin Kong Wu Ho-Su Memorial Hospital, Taipei, ${ }^{7}$ Department of Internal Medicine, National Cheng Kung University Hospital, \\ National Cheng Kung University College of Medicine, Tainan, ${ }^{8}$ Division of Gastroenterology, Department of Internal Medicine, Kaohsiung \\ Municipal Hsiaokang Hospital, Kaohsiung, ${ }^{9}$ Division of Gastroenterology, Department of Internal Medicine, Tri-Service General Hospital, \\ National Defense Medical Center, Taipei, ${ }^{10}$ Division of Colon and Rectal Surgery, Department of Surgery, Mackay Memorial Hospital, Taipei, \\ ${ }^{11}$ Division of Colon and Rectal Surgery, Department of Surgery, Taipei Veterans General Hospital, Taipei, ${ }^{22}$ Department of Surgery, National \\ Yang-Ming University, Taipei, ${ }^{13}$ Department of Internal Medicine, Mackay Memorial Hospital, Taipei, ${ }^{14}$ Department of Pediatrics, National \\ Taiwan University Hospital, Taipei, Departments of ${ }^{15}$ Oncology, ${ }^{16}$ Medical Imaging, and ${ }^{17}$ Pathology and Forensic Medicine, National Taiwan \\ University Hospital, National Taiwan University College of Medicine, Taipei, ${ }^{18}$ Division of Medical Imaging, Department of Radiology, Far \\ Eastern Memorial Hospital, New Taipei City, ${ }^{19}$ Division of Gastroenterology, Department of Internal Medicine, MacKay Memorial Hospital, \\ Taipei, ${ }^{20}$ MacKay Junior College of Medicine, Nursing, and Management, Taipei, ${ }^{21}$ MacKay Medical College, New Taipei City, ${ }^{22}$ Department \\ of Internal Medicine, Far Eastern Memorial Hospital, New Taipei City, ${ }^{23}$ Division of Gastroenterology, Department of Internal Medicine, \\ Kaohsiung Medical University Hospital, Kaohsiung Medical University, Kaohsiung, ${ }^{24}$ Department of Internal Medicine, Kaohsiung Municipal \\ Ta-Tung Hospital, Kaohsiung, ${ }^{25}$ Division of Gastroenterology, Department of Medicine, Taipei City Hospital Renai Branch, Taipei, ${ }^{26}$ Division of \\ Gastroenterology, Department of Internal Medicine, Changhua Christian Hospital, Changhua, Taiwan
}

Ulcerative colitis (UC) is an inflammatory bowel disease characterized by chronic mucosal inflammation of the colon, and the prevalence and incidence of UC have been steadily increasing in Taiwan. A steering committee was established by the Taiwan Society of Inflammatory Bowel Disease to formulate statements on the diagnosis and management of UC taking into account currently available evidence and the expert opinion of the committee. Accurate diagnosis of UC requires thorough clinical, endoscopic, and histological assessment and careful exclusion of differential diagnoses, particularly infectious colitis. The goals of UC therapy are to induce and maintain remission, reduce the risk of complications, and improve quality of life. As outlined in the recommended treatment algorithm, choice of treatment is dictated by severity, extent, and course of disease. Patients should be evaluated for hepatitis B virus and tuberculosis infection prior to immunosuppressive treatment, especially with steroids and biologic agents, and should be regularly monitored for reactivation of latent infection. These consensus statements are also based on current local evidence with consideration of factors, and could be serve as concise and practical guidelines

Received March 13, 2017. Revised May 3, 2017. Accepted May 4, 2017.

Correspondence to Jau-Min Wong, Department of Internal Medicine, National Taiwan University Hospital, National Taiwan University College of Medicine, No.7 Chung-Shan South Road, Taipei 101, Taiwan. Tel: +886-2-23123156, Fax:+886-2-23940049, E-mail: jmwong@ntu.edu.tw

Financial support: None. Conflict of interest: None.

\footnotetext{
(c) Copyright 2017. Korean Association for the Study of Intestinal Diseases. All rights reserved.

This is an Open Access article distributed under the terms of the Creative Commons Attribution Non-Commercial License (http://creativecommons.org/licenses/by-nc/4.0)

which permits unrestricted non-commercial use, distribution, and reproduction in any medium, provided the original work is properly cited.
} 
for supporting clinicians in the management of UC in Taiwan. (Intest Res 2017;15:266-284)

Key Words: Taiwan; Ulcerative colitis; Inflammatory bowel disease; Disease management; Consensus statements

\section{INTRODUCTION}

Ulcerative colitis (UC), a form of IBD, is an immunemediated disorder characterized by chronic mucosal inflammation of the colon and alternating periods of active disease and remission. ${ }^{1}$ While UC is not as common in Asian countries as it is in Western countries, the incidence and prevalence of UC have been steadily rising in Taiwan. ${ }^{2-7}$ Goals of UC therapy are to induce and maintain remission, reduce the risk of complications, and improve quality of life. Choice of treatment depends on disease extent and severity, disease course during follow-up, and patient preference. ${ }^{8}$

Guidelines for the diagnosis and management of UC have been developed in Europe, North America, and Asia Pacific; ${ }^{9-12}$ however, these guidelines are not entirely applicable to clinical practice in Taiwan due to differences in disease distribution and behavior, endemic diseases, and insurance coverage of treatments. The National Health Insurance (NHI) in Taiwan, a mandatory social health insurance system, was established in 1995 and now covers over $99 \%$ of the population..$^{13}$ IBD is classified as a catastrophic illness under NHI, allowing patients with UC to receive treatments that are reimbursed by NHI without copayment. As aspects of the medical environment in Taiwan may be quite different from those of other countries, guidelines for the management of UC that are specific to Taiwan are warranted.

The Taiwan Society of Inflammatory Bowel Disease (TSIBD) established a steering committee with the goal of developing expert consensus statements for the diagnosis and management of UC that take into account recommendations from international guidelines as well as factors with specific relevance to Taiwan. These guidelines are recommendations only and are not to be used in place of clinical judgement. Practitioners must consider individual patient factors as well as the facilities and treatments that are available in their respective institutions in the clinical decisionmaking process.

\section{METHODS}

An expert panel comprising 27 members (gastroenterologists, surgeons, radiologists, and pathologists) was estab- lished by TSIBD. Statements detailing recommendations for the clinical management of UC were drafted by the steering committee after careful consideration of available evidence and existing guidelines, particularly those developed by the European Crohn's and Colitis Organization and the Asian Pacific Association of Gastroenterology. Face-to-face meetings of the entire expert panel were held to allow for open discussion of suggested modifications to wording of the statements and of the evidence for and against each statement. Panel members expressed their agreeance with each finalized statement as "strongly agree," "agree," or "disagree." Consensus was considered to be achieved when $90 \%$ or above of voting members indicated "strongly agree" or "agree." Degree of agreeance reflects the strength of recommendation of each statement.

\section{RESULTS}

\section{Epidemiology}

\section{Statement 1.1}

UC is uncommon in Taiwan, but the incidence and prevalence are increasing.

- Level of agreement: strongly agree $87.5 \%$, agree $12.5 \%$, disagree $0 \%$

Analyses of data from the population-based Taiwan National Health Insurance Research Database (NHIRD) show steadily increasing incidence and prevalence of UC in Taiwan from 1998 to $2010 .^{4-6}$ In 2010, the incidence rate of UC in Taiwan was 1.351 (95\% CI, 1.140-1.562) per 100,000 males and 0.858 (95\% CI, 0.691-1.024) per 100,000 females, approximately double the incidence rate observed in 2000, which was 0.690 (95\% CI, 0.537-0.843) per 100,000 males and 0.386 (95\% CI, 0.269-0.503) per 100,000 females. ${ }^{6}$ Consequently, the prevalence rate of UC in Taiwan has increased more than 5-fold from 1.436 (95\% CI, 1.225-1.671) per 100,000 males and 0.891 (95\% CI, 0.724-1.084) per 100,000 females in 2000 to 7.610 (95\% CI, 7.119-8.125) per 100,000 males and 4.77 (95\% CI, 4.388-5.178) per 100,000 females in 2010. In another National health insurance research database (NHIRD)-based study, the incidence and prevalence 
of UC per 100,000 persons increased from 0.61 and 0.62 , respectively, in 1998 to 0.94 and 7.62 , respectively, in $2008 .{ }^{4}$

Worldwide, the incidence and prevalence of IBD are highest in Europe and North America and the rates have been stable over recent decades in these regions. ${ }^{2,3}$ In Asia, however, IBD has become increasingly prevalent, though still less so than in Western countries. ${ }^{14}$ The UC incidence rates in North American and Europe have been reported to be between $6-15.6$ and $10-20.3$ per 100,000 persons, respectively. ${ }^{15}$ In Asia-Pacific, a recent population-based study involving 9 countries revealed higher incidence of UC in highly urbanized areas, including Guangzhou, China; Hong Kong; and Macau, with crude annual incidence per 100,000 persons of 2.2, 1.7, and, 1.0, respectively. ${ }^{14}$ The increasing incidence of UC in Asian countries, including Taiwan, could be attributed to "Westernization" of lifestyle, though increased disease awareness and diagnosis are also possible explanations. ${ }^{16,17}$

\footnotetext{
Statement 1.2

In Taiwan, there are more male than female UC patients.

- Level of agreement: strongly agree $62.5 \%$, agree $37.5 \%$, disagree $0 \%$
}

According to nationwide studies, the male to female ratio for UC is 1.4 to 1.6 in Taiwan. ${ }^{4-7}$ A population-based analysis of UC incidence in cities in China, Hong Kong, Indonesia, Macau, Malaysia, Singapore, Sri Lanka, and Thailand also showed more male than female patients in UC (male, $57.9 \%) .{ }^{14}$ In contrast, reported incidence of UC was more similar between genders in Japan (male, 53.4\%) and Korea (male, $49.9 \%){ }^{18,19}$ Epidemiological studies conducted in countries with predominantly Caucasian populations have shown either balanced incidence between genders or higher incidence in males. ${ }^{11,20-22}$

\section{Statement 1.3 \\ UC patients in Taiwan exhibit less extraintestinal manifestations compared with patients in Western countries. \\ - Level of agreement: strongly agree 62.5\%, agree 31.5\%, disagree $6.3 \%$}

Extraintestinal manifestations of UC primarily involve the musculoskeletal, cutaneous, hepatobiliary, and ocular systems. ${ }^{23}$ A recent analysis of IBD clinical presentation using data extracted from NHIRD found that $11.2 \%$ of UC cases in Taiwan from 1998 to 2011 exhibited gastrointestinal complications and extraintestinal manifestations. ${ }^{24}$ During the 14-year study period, the prevalence of extraintestinal manifestations increased from $2.8 \%$ to $26.6 \%$. The increase was mostly attributed to a steady rise in the prevalence of peripheral arthritis, the most common of the manifestations, from $1 \%$ in 1998 to $15.4 \%$ in 2011. A hospital-based study conducted at the National Taiwan University Hospital using data from 1988 to 2008 revealed that $4.5 \%$ of UC patients had extraintestinal manifestations, with primary sclerosing cholangitis, reported in $1.5 \%$ of patients, being the most common manifestation in this study. ${ }^{25}$ In contrast, the reported prevalence of extraintestinal manifestations is substantially higher in Western countries, ranging from $21 \%$ to $40 \%{ }^{26,27}$ Less awareness of extraintestinal manifestations in Taiwan and/or real differences due to ethnicity may account for the discrepancy in rates.

\section{Diagnosis}

\section{Statement 2.1}

The diagnosis of UC should be based on medical history, clinical evaluation, typical endoscopic, and histological findings, and especially, the exclusion of an infectious etiology.

- Level of agreement: strongly agree 93.8\%, agree 6.3\%, disagree $0 \%$

No single gold standard for the diagnosis of UC exists. Medical history, clinical evaluation, and typical endoscopic and histological findings must all be taken into consideration for diagnosis. Exclusion of infectious etiology is of exceptional importance, as symptoms of infectious colitis, including those of bacterial, viral, and amebic causes, overlap with those observed with UC. ${ }^{28.33}$

\section{Statement 2.2}

A full medical history of UC should include the onset of symptoms, rectal bleeding, bloody diarrhea, urgency, tenesmus, abdominal pain, incontinence, and features of extra-intestinal manifestations.

- Level of agreement: strongly agree 75\%, agree 25\%, disagree 0\%

Since there is no single diagnostic marker for UC, diagnosis is heavily suspected from the presence of characteristic clinical symptoms. In order to rule out other causes, patients should also be questioned regarding medication use, recent travel, food intolerances, and contact with infectious illnesses. Possible manifestations affecting the eyes, mouth, joints, or skin should be assessed. ${ }^{9}$ 


\begin{abstract}
Statement 2.3
Symptoms of UC are dependent upon extent and severity of disease, and most commonly include diarrhea, bloody mucoid stool, rectal bleeding, and/or rectal urgency.

- Level of agreement: strongly agree $62.5 \%$, agree $37.5 \%$, disagree $0 \%$
\end{abstract}

Severity of clinical parameters, including stool frequency, stool consistency, bloody mucoid stool, rectal bleeding, and rectal urgency, should be considered when classifying a patient's disease activity. Appropriate classification of disease extent and severity determines intensity of treatment. ${ }^{34}$ In clinical trials, clinical disease activity and severity of UC have been commonly scored using Truelove and Witts criteria and the Mayo score. ${ }^{35,36}$ To meet criteria for NHI reimbursement of biologic agents, assessment of disease severity during follow-up using the Mayo score is recommended.

\section{Statement 2.4 \\ Colonoscopy is the mainstay for evaluation of UC. The most use- ful endoscopic feature of UC is diffuse, continuous inflammation (loss of vascular pattern, granularity, friability, and ulceration) involving the rectum with or without proximal extension into the colon. \\ - Level of agreement: strongly agree $87.5 \%$, agree $12.5 \%$, disagree $0 \%$}

Continuous and confluent inflammation involving the rectum with or without proximal continuous extension into the colon is the typical endoscopic finding in treatment-naïve UC patients. There is usually a clear demarcation between inflamed and normal mucosa. Erythema, vascular congestion of the mucosa, loss of visible vascular pattern, granularity, friability, erosions, and superficial ulcerations are endoscopic features of disease activity that is mild to moderate. ${ }^{9,12}$ Severe UC is characterized by spontaneous hemorrhage and mucosal ulcerations, and the presence of deep ulcerations has been associated with poor prognosis. ${ }^{37,38}$

Atypical endoscopic features such as an isolated cecal patch of inflammation, a discontinuous pattern of inflammation, and rectal sparing may mimic CD. Therefore, endoscopic characteristics of UC are essential but not specific for a definitive diagnosis. Pathology findings and clinical presentation are also essential for diagnosis, especially in patients with atypical endoscopic features. In addition to guiding diagnosis, colonoscopy is also useful for determining the extent and severity of lesions. However, colonoscopy should be avoided in patients with acute severe colitis to prevent disease aggravation, procedural delays, and increased risk of perforation. ${ }^{9,39}$

\section{Statement 2.5}

Abdominal radiography is recommended in patients with suspected severe UC when total colonoscopy and barium enema are considered risky.

- Level of agreement: strongly agree $75 \%$, agree $25 \%$, disagree $0 \%$

Plain abdominal radiography is a reliable tool for estimating the extent of active UC and identifying abnormalities such as colonic dilatation, perforation, and obstruction. ${ }^{40} \mathrm{Co}-$ lonic segmental dilatation exceeding $5 \mathrm{~cm}$ in diameter with an irregular mucosal edge outlined by gas on a plain abdominal radiograph correlates strongly with ulceration. ${ }^{41}$ When radiographic findings are unclear or if no abnormalities are found on radiography when they are highly suspected, the patient should undergo more accurate imaging with $\mathrm{CT}{ }^{42}$

\section{Statement 2.6}

The histological diagnosis of UC is based on 2 main components in the lesions: architectural change and inflammatory status.

- Level of agreement: strongly agree 53.3\%, agree 46.7\%, disagree $0 \%$

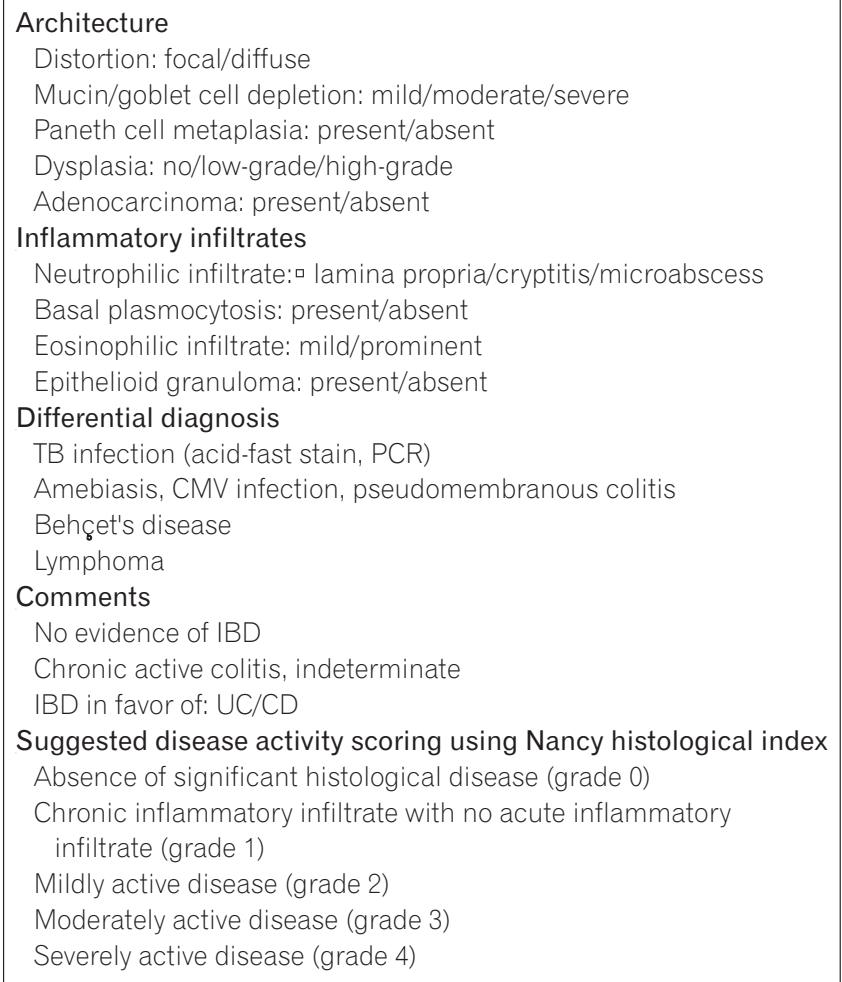

Fig. 1. Recommended checklist for use during histological assessment of UC. Use of this checklist during histological assessment to support thorough evaluation of mucosal architecture and inflammatory infiltrates and exclusion of differential diagnoses is recommended. TB, tuberculosis; CMV, cytomegalovirus. 
The committee recommends the use of a checklist for use during histological assessment to support thorough evaluation and accurate diagnosis (Fig. 1). Change to the mucosal architecture includes glandular distortion (crypt branching or shortening, widening of the crypts, and irregular mucosal surface) and abnormalities in epithelial cells (Paneth cell metaplasia, depletion in goblet cells, and mucin depletion). ${ }^{43-45}$ Pathogenesis of crypt architecture and epithelial cell abnormalities is related to regeneration and repair following previous damage. ${ }^{9,46}$ Histological examination should also include evaluation of the presence of dysplasia and or malignant changes.

Features of inflammatory status include presence of basal plasmacytosis and neutrophilic or eosinophilic infiltration Basal plasmacytosis, also referred to as subcryptal plasma cells, is the presence of plasma cells between the base of the crypts and the muscularis mucosae. ${ }^{43}$ Neutrophils present in the intestinal crypt are a feature of cryptitis. ${ }^{47}$ An increase in eosinophils in the lamina propria has been observed in UC; however, as eosinophil are a general sign of inflammation, they are also present in other forms of colitis. ${ }^{48}$ Conversely, the presence of well-formed epithelioid granulomas in the lamina propria support a diagnosis of CD over UC. ${ }^{49}$ To assess histological disease activity, the committee recommends the use of the Nancy index at initial diagnosis of UC (reasons for recommending the Nancy index are described below in Section 5.3). It is also suggested that previous biopsy slides be reviewed and assessed upon diagnosis of UC.

\footnotetext{
Statement 2.7

A major role of pathology in diagnosing UC is the exclusion of other etiologies, such as infection and malignancy.

- Level of agreement: strongly agree 58.3\%, agree $41.7 \%$, disagree $0 \%$
}

A number of histopathological features distinguish UC from CD. Mucin preservation in association with active disease, epithelioid granulomas in the lamina propria, isolated ileal erosions, and pyloric gland metaplasia are features suggestive of CD. ${ }^{49-51}$ Nevertheless, microscopic distinction between UC and CD can be difficult, often resulting in an intermediate diagnosis of "IBD unclassified." Pathology testing also helps to exclude infectious colitis, such as pseudomembranous, tuberculosis (TB), or cytomegalovirus (CMV) colitis, or malignancy, such as lymphoma or colorectal cancer (CRC).
Statement 2.8
Endoscopic findings of UC are usually typical in treatment-naïve patient, but are likely to be atypical in treatment-experienced pa- tients.
- Level of agreement: strongly agree $84.6 \%$, agree $7.7 \%$, disagree $7.7 \%$

Endoscopic findings of UC differ according to the severity of disease and history of treatments. In treatment-naïve UC patients, endoscopic characteristics are usually typical (as described above in Statement 2.4). In treated cases of UC, endoscopically and histologically discontinuous disease marked by rectal sparing and/or patchy inflammation may develop. ${ }^{52-54}$ In long-standing disease, inflamed mucosa may revert to endoscopically normal mucosa, and the occurrence does not seem to be related to the use of any specific therapy, including rectal therapy ${ }^{52,53}$ In these patients, rectal sparing and patchiness are not necessarily markers of CD, and the diagnosis should not be changed. ${ }^{53,54}$

\section{Specific Considerations}

\section{Statement 3.1}

$\mathrm{HBsAg}$, hepatitis B surface antibody ( $\mathrm{HBs} A b)$, and hepatitis B core antibody $(\mathrm{HBCAb})$ should be routinely checked before treatment initiation, especially before the initiation of immunomodulating and immunosuppressive treatments such as steroids and biologics.

- Level of agreement: strongly agree $46.2 \%$, agree $53.8 \%$, disagree $0 \%$

$\mathrm{HBV}$ infection is endemic in Asia with East Asia having the highest prevalence among all Asian regions-over 8\% of East Asian males aged over 35 years are positive for HBsAg. ${ }^{55}$ Acute $\mathrm{HBV}$ reactivation due to immunosuppressive therapy in patients with IBD can be life-threatening; therefore, to minimize the risk of this complication, HBV screening should be performed prior to the initiation of immunomodulating/immunosuppressive agents for $\mathrm{UC}^{56,57}$

\section{Statement 3.2}

In patients who are $\mathrm{HBsAg}$ and/or $\mathrm{HBcAb}$ positive, HBV DNA quantification is recommended before the initiation of steroid or biologic treatment.

- Level of agreement: strongly agree 69.2\%, agree 30.8\%, disagree $0 \%$ 
In studies assessing outcome of HBV infection in patients with IBD, $25 \%$ to $36 \%$ of patients who were HBsAg-positive experienced liver dysfunction. ${ }^{58,59}$ In HBV-infected patients, most cases of $\mathrm{HBV}$ reactivation have been observed in those treated with 2 or more immunomodulators for a long period of time, were positive for HBV DNA, and/or had not received prophylactic antiviral treatment. ${ }^{57}$

\section{Statement 3.3 \\ In patients with detectable HBV DNA, antiviral treatment for pro- phylaxis of HBV reactivation is recommended and should be dis- cussed with the patient and family, or, at least, HBV DNA should be monitored closely and antiviral treatment initiated when in- crease in HBV DNA titer is observed. \\ - Level of agreement: strongly agree 53.8\%, agree 46.2\%, disagree $0 \%$}

Prophylactic antiviral treatment with nucleotide/nucleoside analogues is recommended in patients with detectable HBV DNA. Antiviral prophylaxis should be initiated 2 weeks before start of immunomodulators and continued for 6 to 12 months after their withdrawal. ${ }^{57}$ Entecavir and tenofovir are preferred in patients with IBD due to their rapid onset of action, high antiviral potency, and low incidence of resistance. ${ }^{57}$

\section{Statement 3.4}

$\mathrm{HBV}$ vaccination is recommended in patients who are negative for $\mathrm{HBsAg}, \mathrm{HBsAb}$, and $\mathrm{HBcAb}$.

- Level of agreement: strongly agree 69.2\%, agree 30.8\%, disagree $0 \%$

Vaccination against HBV is suggested in all patients who are naïve to HBV. However, a lower response rate to HBV vaccination has been observed in patients with $\mathrm{IBD}^{60,61} \mathrm{~A}$ study comparing standard-dose protocol and an accelerated double-dose protocol for HBV vaccination in patients with IBD found a significantly higher seroconversion rate in patients vaccinated with double dose $(75 \%)$ versus standard dose $(41 \%) .^{61}$ Serological response should be assessed 1 to 2 months after completion of vaccination and regularly thereafter, with a recommended HBsAb level of $>100 \mathrm{IU} / \mathrm{L}^{57}$

\footnotetext{
Statement 3.5

Routine screening for latent TB infection with chest X-ray (and if available, interferon-gamma release assays [IGRA]) or tuberculin skin test (TST) is recommended before initiating biologic treatment in patients with UC.

- Level of agreement: strongly agree 83.3\%, agree 16.7\%, disagree $0 \%$
}

Taiwan is a TB-endemic country with a TB prevalence of 97 per 100,000 persons. ${ }^{62}$ Patients with IBD are at higher risk of TB infection than the general population due to the use of immunomodulators including biologic treatments. ${ }^{57}$ Furthermore, diagnosis of TB can be more difficult in patients on anti-tumor necrosis factor (anti-TNF) therapy as their disease is more commonly atypical, extrapulmonary, and disserminated. ${ }^{57}$ In Taiwan, $4.2 \%$ of all reported TB cases in 2010 were extrapulmonary, 5.8\% of which occurred in the gastrointestinal tract. ${ }^{62}$ Careful evaluation of clinical presentation and endoscopic, radiographic, and histological findings is needed to differentiate intestinal TB from CD. All UC patients should be screened for latent TB prior to biologic therapy with a combination of physical examination, chest radiography, and TST or IGRA. It should be noted that results of TST can be affected by prior BCG vaccination, whereas IGRA (QuantiFERON-TB GOLD) is not affected. ${ }^{63}$

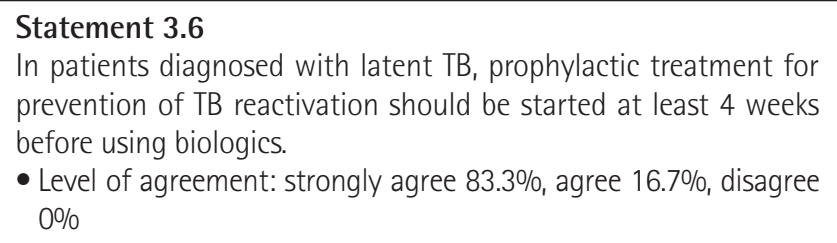

In patients with latent TB, chemoprophylaxis is highly effective in decreasing the risk of $\mathrm{TB}$ reactivation. Treatment of latent TB should follow the current guideline recommendations set forth by the Taiwan Centers for Disease Control. ${ }^{64}$ Biologic therapy should not be initiated until at least 4 weeks of TB treatment has been administered. Consultation with an infectious disease or chest specialist for multidisciplinary care is mandatory.

\section{Statement 3.7}

During biologic therapy, patients should be monitored for signs and symptoms of active TB with chest X-ray (and if available, IGRA) performed at least annually.

- Level of agreement: strongly agree 66.7\%, agree 33.3\%, disagree $0 \%$

For patients with IBD receiving biologic treatment, signs and symptoms of active TB disease should be monitored regularly. Chest radiography, and IGRA if available, should be performed every 6 to 12 months. ${ }^{62}$ Travel and TB contact history should be monitored while the patient is receiving immunosuppressive treatment. An infectious disease specialist should be consulted when necessary. 


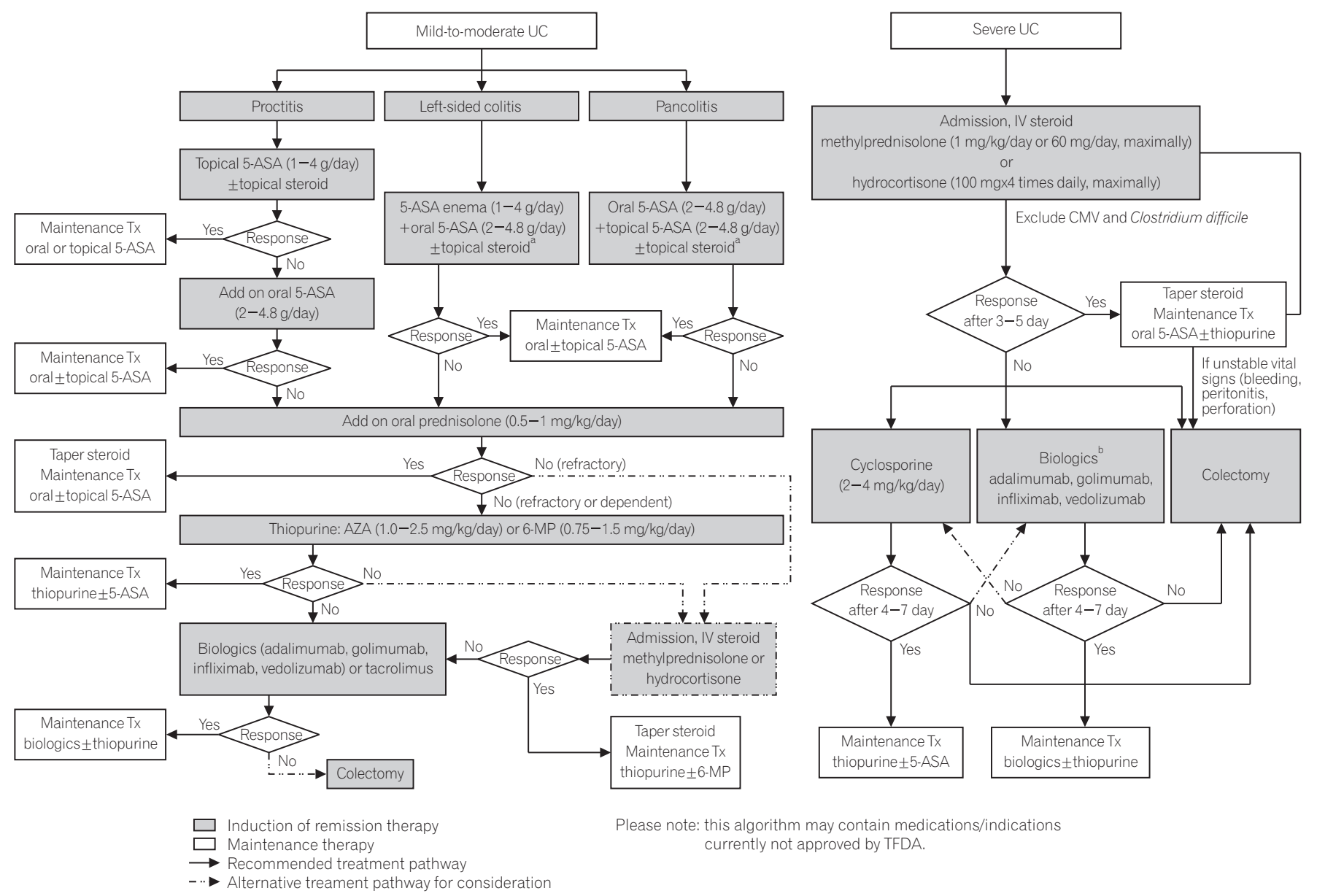

Fig. 2. Recommended algorithm for the treatment of UC. Treatment algorithm for patients with mild-to-moderate or severe UC developed through consensus of an expert panel established by the Taiwan Society of Inflammatory Bowel Disease. Recommendations were formulated after consideration of available evidence and expert opinion as well as the medical environment specific to Taiwan. ${ }^{2}$ Oral budesonide-MMX (9 mg/day) could be an alternative; ${ }^{b}$ For patients with acute severe UC, infliximab is better. 5-ASA, 5-aminosalicylic acid (mesalamine); Tx, treatment; AZA, azathioprine; 6-MP, 6-mercaptopurine; IV, intravenous; CMV, cytomegalovirus; MMX, Multi-Matrix System; TFDA, Taiwan Food and Drug Administration.

\section{Treatment}

\section{Statement 4.1}

The treatment of UC depends on the severity and location of disease. The goals of treatment include induction and maintenance of remission, prevention of complications, and improving quality of life.

- Level of agreement: strongly agree 100\%, agree $0 \%$, disagree $0 \%$

In the management of patients with UC, it is crucial to promptly identify those with severe disease requiring hospital admission to avoid delays in monitoring and treatment. Clinical disease severity can be assessed using the Mayo scoring system, which classifies severity according to frequency of bowel movements, rectal bleeding, endoscopic findings, and physician's global assessment. ${ }^{36}$ Those with mild or moderately active disease can be managed on an out- patient basis, with choice of treatment based on location of disease (proctitis, left-sided colitis, or pancolitis). Treatment is aimed at inducing and maintaining remission, preventing complications, and improving quality of life, and should be individualized according to distribution and pattern of disease, previous response to treatment, and balance between treatment effectiveness and toxicity. The treatment algorithm recommended by the committee is presented in Fig. 2 .

\section{Statement 4.2}

Remission induction therapy for mild-to-moderate proctitis or left-sided colitis:

1. For proctitis, a mesalamine 1-4 g suppository once daily is the preferred initial treatment. Use of mesalamine enemas is an alternative, though suppositories may deliver drug more effectively to the rectum and are better tolerated than enemas. 
2. Left-sided colitis should initially be treated with a mesalamine enema 1-4 g/day combined with oral mesalamine $\geq 2.0-4.8 \mathrm{~g} /$ day.

3. Topical mesalamine is more effective than oral mesalamine alone or topical steroid alone.

4. Combining topical mesalamine (or topical steroid) with oral mesalamine is more effective than any of the agents alone. Budesonide-Multi-Matrix System (MMX) 9 mg/day can be considered as an alternative to topical steroid in left-sided colitis.

5. If symptoms of colitis do not respond to combination therapy described above, the addition of oral prednisolone $0.5-1.0 \mathrm{mg} /$ $\mathrm{kg} /$ day is appropriate.

6. Refractory proctitis or left-sided colitis may require treatment with immunosuppressive and/or biologic agents.

- Level of agreement: strongly agree 75\%, agree 25\%, disagree 0\%

Topical mesalamine is the first line therapy for proctitis and left-sided colitis as results from meta-analyses have shown that rectal mesalamine is more effective than either rectal steroids or oral mesalamine ${ }^{65-67}$ The combination of oral and topical mesalamine may be more effective in patients with distal UC. ${ }^{68}$ The second-generation corticosteroid budesonide in the MMX formulation can be considered as an alternative to topical mesalamine. Despite the high efficacy of systemic corticosteroids, their use is associated with significant safety concerns that affect almost all organ systems. ${ }^{69,70}$ Budesonide-MMX is a novel oral formulation of budesonide that provides targeted and extended release of drug to the entire colon, including the left colon, while minimizing systemic absorption. ${ }^{71,72}$ In the CORE I study which included patients with active, mild-to-moderate UC, rates of combined clinical and endoscopic remission at week 8 were $17.9 \%$ with budesonide-MMX 9 mg and 12.1\% with mesalamine $2.4 \mathrm{~g}$, compared with $7.4 \%$ with placebo $(P=0.014$ and $P=0.22){ }^{73}$ Rates of remission were $17.4 \%$ with budesonide-MMX $9 \mathrm{mg}$ and $12.6 \%$ with controlled ilealrelease budesonide $9 \mathrm{mg}$, compared with $4.5 \%$ with placebo ( $P=0.005$ and $P=0.048)$ at week 8 in the phase III colonic release (CORE) I study. ${ }^{74}$ Use of systemic corticosteroids is appropriate in patients not responding to initial treatment. ${ }^{10}$ In UC patients with refractory disease, azathioprine, mercaptopurine, tacrolimus, or biologic agents may be required.

\section{Statement 4.3}

Remission induction therapy for mild-to-moderate pancolitis:

1. Mild-to-moderate pancolitis should initially be treated with oral mesalamine 2.0-4.8 g/day, which should be combined with topical mesalamine if tolerated to increase remission rate.

2. Once daily dosing of mesalamine is as effective as divided doses.
3. Systemic steroids are appropriate if symptoms of active colitis do not respond to mesalamine.

4. Patients with steroid-dependent disease should be treated with immunomodulators.

5. Patients with steroid- or immunomodulator-refractory disease should be treated with biologics or tacrolimus, although admission for parenteral steroid therapy could also be considered.

- Level of agreement: strongly agree $76.9 \%$, agree $23.1 \%$, disagree $0 \%$

In a randomized trial of 127 patients, combination therapy with oral mesalamine $4 \mathrm{~g}$ /day and a $1 \mathrm{~g}$ mesalamine enema was superior to oral therapy alone for inducing remission in patients with extensive mild-to-moderate UC ${ }^{75}$ BudesonideMMX can be considered as an alternative to topical mesalamine. Several randomized trials have shown noninferiority of once daily dosing of mesalamine to divided doses in achieving remission. ${ }^{76-78}$ Further treatment of patients with mild-to-moderate pancolitis unresponsive to mesalamine is the same as that for patients with mild-to-moderate proctitis or left-sided colitis unresponsive to mesalamine.

\section{Statement 4.4}

Remission induction therapy for severe UC of any extent:

1. Patients with severe colitis of any extent should be admitted for intensive treatment.

2. Intravenous methylprednisolone (maximum dose $1 \mathrm{mg} / \mathrm{kg} / \mathrm{day}$ or $60 \mathrm{mg} /$ day) or hydrocortisone (maximum dose $100 \mathrm{mg} 4$ times daily) with or without oral mesalamine is generally prescribed.

3. Administration of intravenous antibiotics is suggested when signs of systemic toxicity or infection are present.

4. The response to intravenous corticosteroid is best assessed objectively between days 3 and 5 of therapy. Biologic agents, cyclosporine, or tacrolimus may be appropriate as second-line therapy in patients not responding to intravenous corticosteroids.

5. If there is no improvement within 4 to 7 days of second-line therapy, colectomy should be considered, discussed, and recommended.

- Level of agreement: strongly agree $84.6 \%$, agree $15.4 \%$, disagree $0 \%$

Patients with acute severe UC must be admitted for intensive treatment as the condition could be life threatening. A Mayo score $\geq 11$ or any sign of systemic toxicity, such as tachycardia, fever, and elevated ESR or CRP indicates severe UC. Intravenous corticosteroids effectively induce remission in severe UC and is the mainstay of treatment. ${ }^{79,80}$ Methylprednisolone (maximum $1 \mathrm{mg} / \mathrm{kg} /$ day or $60 \mathrm{mg} /$ day) or hydrocortisone $100 \mathrm{mg} 4$ times daily is appropriate; higher doses have not been shown to improve outcomes. ${ }^{10,80}$ 
Infectious causes, including CMV and Clostridium difficile, should be ruled out.

Patients with severe UC that is refractory to intravenous steroids (as assessed between the 3rd and 5th day after initiation of therapy) should be treated with cyclosporine or biologic agents as 2nd-line therapy. A randomized trial has shown comparable colectomy rates between patients with steroid-refractory severe UC treated with cyclosporine or infliximab. ${ }^{81}$ Patient-specific factors and the risk of adverse events should be considered in the selection of second-line therapy.

Colectomy is indicated if the patient fails to respond to second-line therapy within 4 to 7 days. Colectomy may also be appropriate upon admission or after failure of intravenous corticosteroids. Decision-making regarding the timing of colectomy for severe UC can be aided by clinical (stool frequency and temperature), and biochemical markers (CRP, ESR, albumin, and pH) as well as radiological and endoscopic findings (colonic dilatation, presence of ileus, and depth of ulceration). ${ }^{10,82-86}$ When indicated, colectomy should be performed timely as delayed surgery in patients with acute severe UC who do not respond to medical therapy is associated with poorer postoperative outcomes. ${ }^{87}$

\section{Statement 4.5}

Maintenance therapy for UC:

1. The goal of maintenance therapy in UC is to maintain clinically and endoscopically defined steroid-free remission.

2. Oral mesalamine, at a minimum effective dose of $1.2 \mathrm{~g} /$ day, is the first-line maintenance treatment. Rectal mesalamine is the first-line treatment for maintenance in proctitis and an alternative treatment in left-sided colitis.

3. Steroids are not recommended for maintenance of remission.

4. Immunomodulators should be used in steroid-dependent patients for maintenance therapy. The currently recommended immunosuppressant treatment is azathioprine $1.0-2.5 \mathrm{mg} / \mathrm{kg}$.

5. Maintenance with anti-TNF therapy is preferred in patients with prior failure of thiopurines. In patients responding to antiTNF agents for induction therapy, maintaining remission with an immunosuppressant or continued anti-TNF therapy with or without thiopurines are both appropriate.

- Level of agreement: strongly agree $61.5 \%$, agree $38.5 \%$, disagree $0 \%$

Remission in UC is generally defined as 1 or 2 stools a day without rectal bleeding, fever, or tachycardia and mucosal healing on endoscopic assessment with complete discontinuation of corticosteroids. ${ }^{10,35}$ In a Cochrane Review published in 2016, use of oral mesalamine was significantly associated with lower risk of relapse compared with placebo (RR, 0.69; 95\% CI, 0.62-0.77) ${ }^{88}$ Higher dose of oral mesala- mine was not associated with a higher incidence of adverse effects and may be beneficial in maintaining remission in patients with extensive UC or frequent relapses. In addition, meta-analysis results found once daily administration of oral mesalamine to be as effective as conventional dosing ( 2 or 3 times daily) for maintenance of remission. Topical therapy with suppositories is most effective for proctitis as it delivers the active compound directly to the site of inflammation. ${ }^{89}$ For left-sided colitis, topical therapy with enemas, foams, or gel can be considered due to their ability to spread proximally. ${ }^{90}$ The combination of oral mesalamine and intermittent rectal mesalamine is associated with higher remission rates and should be considered for second-line maintenance therapy. ${ }^{10}$

While steroids are standard treatment for remission induction in UC, first-generation steroids, such as prednisone, are not advised for use as maintenance treatment due to adverse events associated with long-term use, including increased risk of serious infections, bone disease, the development of cushingoid features, and increased risk of mortality. ${ }^{91}$ In a study evaluating the efficacy of budesonide-MMX for the maintenance of remission, the probability of relapse in patients receiving budesonide-MMX $6 \mathrm{mg}$ was $40.9 \%$ compared to $59.7 \%$ in those receiving placebo, though the rate of maintained remission at month 12 was not significantly different between groups. ${ }^{71}$ Further studies are needed to evaluate the benefit of budesonide-MMX in maintenance of UC remission.

Azathioprine is recommended for maintenance of remission in patients with steroid-dependent UC. In a Cochrane Review of trials evaluating the efficacy of thiopurines for maintenance of remission in UC, azathioprine was shown to be superior to placebo (OR for failure to retain remission, $0.41 ; 95 \% \mathrm{CI}, 0.24-0.70) .{ }^{92}$ In addition, a randomized trial including patients with active steroid-dependent UC found that those treated with azathioprine for 6 months were significantly more likely to achieve steroid-free remission than those treated with mesalamine (OR, 4.78; 95\% CI, 1.57-14.5) ${ }^{93}$ Furthermore, maintenance with azathioprine is recommended for patients receiving cyclosporine or tacrolimus for induction of remission. Use of thiopurines has been associated with reduced risk of colectomy after remission induction with cyclosporine. ${ }^{94,95}$

The currently available anti-TNF therapies (infliximab, adalimumab, and golimumab) appear to have similar efficacy and safety profiles. ${ }^{96-98}$ Choice of agent depends on availability, route of administration, patient preference, and cost. Infliximab, however, is presently the only anti-TNF 
agent with evidence specifically in support of its efficacy in steroid-refractory acute severe UC. ${ }^{99,100}$ A biologic of a different mechanistic class is vedolizumab, an anti- $\alpha 4 \beta 7$-integrin agent which inhibits lymphocyte recruitment to the inflamed gut. Vedolizumab has been shown to be efficacious in inducing and maintaining clinical remission in patients with UC. ${ }^{101}$ Reassessment of disease activity, exclusion of complications, and consideration of surgery should be carried out for loss of response to anti-TNF therapy. An increase in dose or dosing frequency should be attempted prior to switching to another biologic agent, as switching reduces future therapeutic options. ${ }^{10}$

Major safety concerns with biologic therapy include infection and malignancy ${ }^{56}$ Use of anti-TNF agents increases the risk of opportunistic infections, such as reactivation of TB. ${ }^{102}$ The risk is further increased with long-term use of anti-TNF agents in combination with other immunosuppressive therapies. ${ }^{103}$ Hepatosplenic T-cell lymphoma, a rare and usually fatal cancer, has been reported in young patients who were treated with combination infliximab and a thiopurine for IBD. ${ }^{104,105}$ Though the role of anti-TNF agents in the pathogenesis of hepatosplenic T-cell lymphoma has not been established, the long term use of combined anti-TNF therapy and a thiopurine should be avoided in young, particularly male, patients.

\section{Monitoring}

\section{1) Endoscopy}

\section{Statement 5.1.1 \\ Mucosal healing in UC is associated with lower risk of clinical re- lapse, hospitalization, colectomy, and colitis-associated neoplasia. Routine endoscopy for patients in clinical remission is unneces- sary, unless it is likely to change management. \\ - Level of agreement: strongly agree 100\%, agree 0\%, disagree 0\%}

Patients who achieve endoscopic remission (normallooking mucosa with no significant inflammation) have longer duration of remission, are less likely to relapse, and have a lower risk of future colectomy. ${ }^{106-108}$ In addition, mucosal healing is strongly associated with a reduced risk of cancer in patients with UC. ${ }^{109}$ While endoscopy can be helpful in identifying subclinical inflammation, the procedure is invasive and should not be used for routine monitoring of patients in clinical remission. Endoscopic assessment should be performed only in patients who are not responding to treatment and require change in therapy or for cancer surveillance. ${ }^{110}$

\section{Statement 5.1.2}

Endoscopic reassessment should be considered in cases of relapse, refractoriness, new symptoms, or when surgery is considered.

- Level of agreement: strongly agree 92.3\%, agree 7.7\%, disagree $0 \%$

Endoscopy objectively assesses disease activity and is a more reliable indicator of disease severity than subjective symptoms. ${ }^{111}$ Severity of colitis assessed by endoscopy can help predict response to treatment and need for surgery in patients with acute UC. In a review of 85 patients with acute UC, those with severe endoscopic colitis (defined as extensive deep ulcerations, mucosal detachment on ulceration edge, well-like ulcerations, and large mucosal abrasion) were less likely to improve on medical treatment ( $7 \%$ vs. $77 \%$ ) and more likely to require surgery (93\% vs. $23 \%$ ) than those with moderate endoscopic colitis (defined as erythematous and swollen mucosa, superficial ulcerations, and deep ulcerations covering $<10 \%$ of the mucosal area). ${ }^{38}$

\section{Statement 5.1.3}

Endoscopy during an acute flare is an important tool in determining the severity of the disease flare and coexistent enteric infections. Most patients will only require flexible sigmoidoscopy; total colonoscopy may potentially be harmful.

- Level of agreement: strongly agree 84.6\%, agree 15.4\%, disagree $0 \%$

During exacerbations in patients with UC, endoscopy may define disease activity and help identify the presence of superimposed colitis, including $\mathrm{CMV}, C$. difficile, or ischemic colitis. ${ }^{111}$ Total colonoscopy should not be performed during an acute flare due to the risk of colonic perforation. ${ }^{9}$ In patients with acute severe colitis, criteria for disease severity, including hemorrhagic mucosa with deep ulceration, mucosal detachment on ulceration edge, and well-like ulcerations, can be assessed with flexible sigmoidoscopy. ${ }^{9}$

\section{2) Biochemistry Tests}

\section{Statement 5.2.1}

Fecal calprotectin is the most sensitive and noninvasive biomarker useful for detecting colonic inflammation and assessing disease activity in UC (correlating with endoscopic indices, relapse, and response to treatment).

- Level of agreement: strongly agree 76.9\%, agree 23.1\%, disagree $0 \%$

Although endoscopy with biopsies is the gold standard for assessing intestinal inflammation, it is an invasive proce- 
dure. Fecal calprotectin, a protein derived from neutrophils, is markedly elevated in infectious and inflammatory conditions, including IBD, and correlated well with endoscopic activity in IBD patients in a study conducted Taiwan. ${ }^{12,113}$ Patients with endoscopically and histologically active UC have higher fecal calprotectin levels than those with mildly active or inactive UC, and calprotectin concentration correlates positively with advancing histological inflammation and negatively with endoscopic remission. ${ }^{114,115}$ As a predictor of relapse in UC, studies have shown the sensitivity and specificity of calprotectin to be approximately $90 \%$ and $80 \%$, respectively. ${ }^{116,117}$ In addition, reduction in fecal calprotectin concentration in response to UC treatment corresponds with clinical, endoscopic, and histological improvement. ${ }^{118,119}$ However, while fecal calprotectin may be useful in determining whether symptoms are due to disease flares or noninflammatory causes in patients with IBD, as with all fecal biomarkers, it lacks the specificity to differentiate between types of gut inflammation. ${ }^{120,121}$

\section{Statement 5.2.2}

CRP and ESR are useful markers for assessing response to treatment in UC, especially in severe colitis.

- Level of agreement: strongly agree $76.9 \%$, agree $23.1 \%$, disagree $0 \%$

CRP and ESR are inflammatory markers that are used for determining the severity of IBD. In patients with UC, ESR, and CRP have a significant correlation with clinical activity scores; however, ESR and CRP levels have been found to be normal in proctitis. ${ }^{122-124}$ In acute severe colitis, elevated CRP is associated with elevated ESR, anemia, and hypoalbuminemia, and has been shown to be predictive of the need for colectomy. ${ }^{125,126}$

\footnotetext{
Statement 5.2.3

Microbial testing, including for $C$. difficile and CMV infection, is recommended in UC patients with severe or refractory relapse.

- Level of agreement: strongly agree 84.6\%, agree 15.4\%, disagree $0 \%$
}

Use of corticosteroids and immunomodulators has been associated with increased risk of $C$. difficile-associated diarrhea in patients with IBD. ${ }^{127,128}$ During a severe or refractory relapse, a stool analysis for $C$. difficile should be performed. As $C$. difficile is the most common infectious cause of healthcare-associated diarrhea, screening for $C$. difficile should be done in UC patients who are hospitalized or have a previous history of antibiotic use. ${ }^{9,128,129}$

Reactivation of latent CMV infection can occur with use of immunomodulators for UC, but the reactivation is usually subclinical and self-limited. ${ }^{130,131}$ Since only a minority of CMV infections lead to clinical disease, routine screening for CMV infection is not necessary in patients with UC. ${ }^{57}$ However, in patients with severe steroid-resistant colitis while receiving immunomodulators, antiviral therapy should be initiated and immunomodulators may need to be discontinued when CMV is detected in the mucosa.

\section{3) Pathology}

Histological disease activity of UC is commonly assessed using the Riley index and the Geboes index, though neither has been fully validated. ${ }^{132,133}$ In 2015, Marchal-Bressenot et al. ${ }^{134}$ published the development and validation results of the Nancy index for UC, an easy to use scoring system that was shown to have good intraobserver and interobserver reliability as well as responsiveness. The Nancy index comprises 3 histological items (ulceration, acute inflammatory infiltrate, and chronic inflammatory infiltrate) defining 5 levels of disease activity: grade 0 (absence of significant histological disease activity), grade 1 (presence of chronic inflammatory infiltrate with no acute inflammatory infiltrate), grade 2 (presence of mild acute inflammatory infiltrate indicating mildly active disease), grade 3 (presence of moderate or severe acute inflammatory infiltrate indicating moderately active disease), and grade 4 (presence of ulceration indicating severely active disease). Monitoring of IBD mainly depends on the inflammatory status of specimens; however, the associated clinical presentation must also be considered in addition to the histological features. The committee recommends using the Nancy index to assess histological disease activity at initial diagnosis and during follow-up. The recently developed Robarts histopathology index is another validated scoring system for the evaluation of UC which was shown to be reproducible and responsive. ${ }^{135}$ However, a comparison study between the Nancy index and the Robarts histopathology index has not yet been conducted.

\section{Surgery}

\footnotetext{
Statement 6.1

Bowel perforation, massive bleeding, toxic megacolon, severe colitis unresponsive to medical treatment, intolerable side effects to medical treatment, high-grade dysplasia, and carcinoma are indications for surgical treatment in patients with UC.

- Level of agreement: strongly agree $84.6 \%$, agree $15.4 \%$, disagree $0 \%$
} 


\section{Cancer Surveillance}

Delay in surgical treatment in indicated UC patients is associated with high morbidity and mortality. ${ }^{12,136}$ Restorative proctocolectomy with ileal pouch anal anastomosis (IPAA) is one of the elective surgical procedures for UC. A staged procedure (colectomy first) is usually recommended in acute severe UC when patients do not respond to medical therapy. Ileorectal anastomosis can be considered as an alternative to IPAA in special cases, such as for preservation of sexual function and fertility, as studies have shown that open IPAA is associated with sexual dysfunction and reduced female fecundity. ${ }^{137-140}$ While ileorectal anastomosis does not disturb sphincter function nor impair fertility, the retained rectum remains at risk for dysplasia and carcinoma and long-term surveillance is advised. ${ }^{141}$

When performing restorative proctocolectomy, a 2- or 3 -stage procedure with a temporary covering loop ileostomy is recommended. Compared with a one-stage procedure, a 2-stage procedure may reduce the risk of anastomotic leakage, peritonitis, and pelvic sepsis. ${ }^{142}$ Patients who are urgent cases, debilitated by colitis, taking high doses of steroids, have serious associated disease, or have indeterminate colitis should not undergo a 1-stage procedure. ${ }^{142}$

The most common complication of IPAA is pouchitis, a nonspecific inflammation of the ileal reservoir, which occurs in up to $50 \%$ of patients 10 years after IPAA. ${ }^{137,143}$ Symptoms of pouchitis include increased stool frequency and liquidity, abdominal cramping, urgency, tenesmus, and pelvic discomfort. ${ }^{144,145}$ Other etiologies, including irritable pouch syndrome, cuffitis, CD of the pouch, and postoperative complications such as anastomotic leak or stricture, may mimic pouchitis; therefore, endoscopic and histological findings should be considered in diagnosis. ${ }^{143,146}$ Patients who develop typical signs and symptoms of acute pouchitis after IPAA should be treated with antibiotics, such as a 2-week course of metronidazole $20 \mathrm{mg} / \mathrm{kg} /$ day or ciprofloxacin $1 \mathrm{~g} /$ day. Chronic pouchitis, persistent symptoms that do not respond to conventional therapy, is a leading cause of pouch failure and should be treated with combination antibiotic therapy or oral budesonide. ${ }^{143,146}$

\section{Statement 7.1}

UC patients are at increased risk of developing CRC. Risk of CRC varies with the extent and duration of $\mathrm{UC}$, family history of $\mathrm{CRC}$ and the presence/absence of primary sclerosing cholangitis.

- Level of agreement: strongly agree 92.3\%, agree 7.7\%, disagree $0 \%$

Between 2000 and 2010, 5 cases of CRC were observed among 2,098 patients with UC in Taiwan, corresponding to a prevalence rate of $0.24 \%$ and an incidence rate of 60.19 per 100,000 persons. ${ }^{6}$ The incidence rate of CRC in UC patients is markedly higher than that in the overall population in Taiwan, which was 34.75 per 100,000 persons between 2000 and 2006. ${ }^{147}$ Histological inflammation is an established risk factor for the development of CRC and the risk of developing CRC dramatically increases with longstanding UC. In a meta-analysis including 19 studies, cumulative risk of CRC in UC was $1.6 \%$ at 10 years, $8.3 \%$ at 20 years, and $18.4 \%$ at 30 years. ${ }^{148}$ In a case-control study of UC patients, family history of sporadic CRC was an independent risk factor for CRC; those with CRC were twice as likely to have a family history of sporadic CRC than those without CRC. ${ }^{149}$ Patients with both primary sclerosing cholangitis and UC have been shown to be at higher risk of CRC than UC patients without primary sclerosing cholangitis, with an adjusted RR of $3.15 .^{150}$

\section{Statement 7.2}

Surveillance for CRC should start 8 years after diagnosis in extensive type UC and 12 years after diagnosis in left-sided colitis.

- Level of agreement: strongly agree 61.5\%, agree 38.5\%, disagree $0 \%$

As earlier detection of CRC improves prognosis, surveillance colonoscopies should be performed at defined intervals to identify dysplastic change in colonic mucosa, which is associated with an increased risk of CRC. ${ }^{143,151}$ Frequency of endoscopic surveillance, varying from 1 to 4 years, should be tailored to the individual patient's risk factor profile. ${ }^{143}$ Annual surveillance colonoscopy with biopsies should be performed regularly after 8 to 10 years of first manifestation. UC patients with IPAA may not require regular surveillance as the risk for CRC in such patients is low. Surveillance colonoscopies should be performed in remission to avoid misinterpretation of inflammatory activity. Chromoendoscopy with targeted biopsies is the preferred procedure as it has been shown to yield higher detection rates of intraepithelial neoplasias in UC than white-light endoscopy with random biopsies. ${ }^{152}$ 
In addition to CRC, patients with UC may be at increased risk of other cancers. Although analysis of data from 1998 to 2013 collected from NHIRD showed no increase in overall cancer risk in patients with UC in Taiwan, compared with control patients, a significant standardized incidence ratio (SIR) was found in UC patients for hematological malignancies (SIR, 2.51), non-Hodgkin's lymphoma (SIR, 3.0), and urinary tract cancers $(\mathrm{SIR}, 2.05) .^{7} \mathrm{In}$ a population-based study conducted in Europe, UC was associated with an increased risk of gastrointestinal cancers, specifically cancer of the liver (SIR, 1.6) and gallbladder (SIR, 2.5), as well as a slightly increased risk of extraintestinal cancers (SIR, 1.1). ${ }^{153}$ Risk of cholangiocarcinoma in patients with IBD is significantly higher in patients with UC, and primary sclerosing cholangitis has been found to be a major risk factor for cholangiocarcinoma. ${ }^{154,155}$ In addition, a diagnosis of dysplasia or cancer of the colon or rectum prior to IPAA has been shown to be a risk factor for pouch dysplasia or adenocarcinoma in patients with UC. ${ }^{156}$

\section{CONCLUSIONS}

These consensus statements on the diagnosis and management of UC in Taiwan were developed by an expert panel established by TSIBD through a rigorous process of discussion and voting. Available evidence and expert opinion were carefully considered and recommendations were formulated taking into account the medical environment specific to Taiwan, including endemic diseases, availability of treatments, and treatment coverage by NHI. The recommended treatment algorithm was developed with the aim of providing a concise and practical tool for supporting clinicians in Taiwan in their clinical decision making.

Accurate diagnosis of UC after thorough exclusion of differential diagnoses and careful assessment of disease severity from clinical, endoscopic, and histological findings are critical in optimal patient management. In mild-to-moderate UC, mesalamine is an established treatment for remission induction. Growing evidence support the use of budesonideMMX as an additional treatment option. In both mild-tomoderate and severe UC, biologic agents represent an important later line of therapy, though their use may bring increased risk of HBV and TB reactivation, an important consideration in patients in Taiwan. As the recommendations presented are based on currently available evidence, the statements may require revision in the future as more data for existing and novel therapies for the treatment of UC emerge.

\section{ACKNOWLEDGEMENTS}

We would like to express our appreciation to all 27 members of the expert panel for their devotion to the development of these guidelines. Special thanks to C.C.L and C.H.C. for their rigorous review of the draft and S.C.W. for his assistance in manuscript editing. Thank you to the panel and to J.M.W. for their efforts in the translation of the guidelines into Mandarin Chinese and the making of the pocket book edition for clinical practice.

\section{REFERENCES}

1. Feuerstein JD, Cheifetz AS. Ulcerative colitis: epidemiology, diagnosis, and management. Mayo Clin Proc 2014;89:1553 1563.

2. Molodecky NA, Soon IS, Rabi DM, et al. Increasing incidence and prevalence of the inflammatory bowel diseases with time, based on systematic review. Gastroenterology 2012;142:46-54.

3. Cosnes J, Gower-Rousseau C, Seksik P, Cortot A. Epidemiology and natural history of inflammatory bowel diseases. Gastroenterology 2011;140:1785-1794.

4. Wei SC, Lin MH, Tung CC, et al. A nationwide populationbased study of the inflammatory bowel diseases between 1998 and 2008 in Taiwan. BMC Gastroenterol 2013;13:166.

5. Chuang CH, Lin SH, Chen CY, Sheu BS, Kao AW, Wang JD. Increasing incidence and lifetime risk of inflammatory bowel disease in Taiwan: a nationwide study in a low-endemic area 1998-2010. Inflamm Bowel Dis 2013;19:2815-2819.

6. Kuo CJ, Yu KH, See LC, et al. The trend of inflammatory bowel diseases in Taiwan: a population-based study. Dig Dis Sci 2015;60:2454-2462.

7. Wang LH, Yang YJ, Cheng WC, Wang WM, Lin SH, Shieh CC. Higher risk for hematological malignancies in inflammatory bowel disease: a nationwide population-based study in Taiwan. Am J Gastroenterol 2016;111:1313-1319.

8. Danese S, Fiocchi C. Ulcerative colitis. N Engl J Med 2011;365: 1713-1725.

9. Dignass A, Eliakim R, Magro F, et al. Second European evidence-based consensus on the diagnosis and management of ulcerative colitis part 1: definitions and diagnosis. J Crohns Colitis 2012;6:965-990.

10. Dignass A, Lindsay JO, Sturm A, et al. Second European evidence-based consensus on the diagnosis and management of ulcerative colitis part 2: current management. J Crohns Colitis 2012;6:991-1030. 
11. Talley NJ, Abreu MT, Achkar JP, et al. An evidence-based systematic review on medical therapies for inflammatory bowel disease. Am J Gastroenterol 2011;106 Suppl 1:S2-S25.

12. Ooi CJ, Fock KM, Makharia GK, et al. The Asia-Pacific consensus on ulcerative colitis. J Gastroenterol Hepatol 2010;25:453468.

13. Lan JY. Achieving and sustaining universal health coverage: fiscal reform of the National Health Insurance in Taiwan [published online ahead of print October 25, 2016]. Appl Health Econ Health Policy. doi:10.1007/s40258-016-0286-6.

14. Ng SC, Tang W, Ching JY, et al. Incidence and phenotype of inflammatory bowel disease based on results from the Asiapacific Crohn's and colitis epidemiology study. Gastroenterology 2013;145:158-165.e2.

15. Loftus EV Jr. Clinical epidemiology of inflammatory bowel disease: incidence, prevalence, and environmental influences. Gastroenterology 2004;126:1504-1517.

16. Thia KT, Loftus EV Jr, Sandborn WJ, Yang SK. An update on the epidemiology of inflammatory bowel disease in Asia. Am J Gastroenterol 2008;103:3167-3182.

17. Prideaux L, Kamm MA, De Cruz PP, Chan FK, Ng SC. Inflammatory bowel disease in Asia: a systematic review. J Gastroenterol Hepatol 2012;27:1266-1280.

18. Asakura K, Nishiwaki Y, Inoue N, Hibi T, Watanabe M, Takebayashi T. Prevalence of ulcerative colitis and Crohn's disease in Japan. J Gastroenterol 2009;44:659-665.

19. Yang SK, Yun S, Kim JH, et al. Epidemiology of inflammatory bowel disease in the Songpa-Kangdong district, Seoul, Korea, 1986-2005: a KASID study. Inflamm Bowel Dis 2008;14:542549.

20. Bernstein CN, Wajda A, Svenson LW, et al. The epidemiology of inflammatory bowel disease in Canada: a population-based study. Am J Gastroenterol 2006;101:1559-1568.

21. Gearry RB, Richardson A, Frampton CM, et al. High incidence of Crohn's disease in Canterbury, New Zealand: results of an epidemiologic study. Inflamm Bowel Dis 2006;12:936-943.

22. Molinié F, Gower-Rousseau C, Yzet T, et al. Opposite evolution in incidence of Crohn's disease and ulcerative colitis in Northern France (1988-1999). Gut 2004;53:843-848.

23. Larsen S, Bendtzen K, Nielsen OH. Extraintestinal manifestations of inflammatory bowel disease: epidemiology, diagnosis, and management. Ann Med 2010;42:97-114.

24. Hsu YC, Wu TC, Lo YC, Wang LS. Gastrointestinal complications and extraintestinal manifestations of inflammatory bowel disease in Taiwan: a population-based study. J Chin Med Assoc 2017;80:56-62.
25. Wei SC, Shieh MJ, Chang MC, Chang YT, Wang CY, Wong JM. Long-term follow-up of ulcerative colitis in Taiwan. J Chin Med Assoc 2012;75:151-155.

26. Su CG, Judge TA, Lichtenstein GR. Extraintestinal manifestations of inflammatory bowel disease. Gastroenterol Clin North Am 2002;31:307-327.

27. Bernstein CN, Blanchard JF, Rawsthorne P, Yu N. The prevalence of extraintestinal diseases in inflammatory bowel disease: a population-based study. Am J Gastroenterol 2001;96:1116-1122.

28. Tedesco FJ, Hardin RD, Harper RN, Edwards BH. Infectious colitis endoscopically simulating inflammatory bowel disease: a prospective evaluation. Gastrointest Endosc 1983;29:195197.

29. Chodos JE. Campylobacter infection mimicking ulcerative colitis. N Y State J Med 1986;86:22-23.

30. Siegal D, Syed F, Hamid N, Cunha BA. Campylobacter jejuni pancolitis mimicking idiopathic ulcerative colitis. Heart Lung 2005;34:288-290.

31. Dunzendorfer T, Kasznica J. Amebic and/or ulcerative colitis? Gastrointest Endosc 1998;48:450-451.

32. Ibrahim TM, Iheonunekwu N, Gill V, Vantapool H. Differentiating amoebic ulcero-haemorrhagic recto-colitis from idiopathic inflammatory bowel disease: still a diagnostic dilemma. West Indian Med J 2005;54:210-212.

33. Misra SP, Misra V, Dwivedi M, Singh PA. Colonic tuberculosis mimicking ulcerative colitis. J Assoc Physicians India 1998;46:309-310.

34. Sands BE. From symptom to diagnosis: clinical distinctions among various forms of intestinal inflammation. Gastroenterology 2004;126:1518-1532.

35. Truelove SC, Witts LJ. Cortisone in ulcerative colitis: final report on a therapeutic trial. Br Med J 1955;2:1041-1048.

36. Schroeder KW, Tremaine WJ, Ilstrup DM. Coated oral 5-aminosalicylic acid therapy for mildly to moderately active ulcerative colitis: a randomized study. N Engl J Med 1987;317:16251629.

37. Pera A, Bellando P, Caldera D, et al. Colonoscopy in inflammatory bowel disease: diagnostic accuracy and proposal of an endoscopic score. Gastroenterology 1987;92:181-185.

38. Carbonnel F, Lavergne A, Lémann M, et al. Colonoscopy of acute colitis: a safe and reliable tool for assessment of severity. Dig Dis Sci 1994;39:1550-1557.

39. Hibi T, Ueno F, Matsuoka K, Lee TC. Guidelines for the management of ulcerative colitis in Japan: developed through integration of evidence and consensus among experts. IBD Res 2010;4:189-239. 
40. Prantera C, Lorenzetti R, Cerro P, Davoli M, Brancato G, Fanucci A. The plain abdominal film accurately estimates extent of active ulcerative colitis. J Clin Gastroenterol 1991;13:231234.

41. Buckell NA, Williams GT, Bartram CI, Lennard-Jones JE. Depth of ulceration in acute colitis: correlation with outcome and clinical and radiologic features. Gastroenterology 1980;79:1925.

42. Panes J, Bouhnik Y, Reinisch W, et al. Imaging techniques for assessment of inflammatory bowel disease: joint ECCO and ESGAR evidence-based consensus guidelines. J Crohns Colitis 2013;7:556-585.

43. Washington K, Greenson JK, Montgomery E, et al. Histopathology of ulcerative colitis in initial rectal biopsy in children. Am J Surg Pathol 2002;26:1441-1449.

44. Jenkins D, Balsitis M, Gallivan S, et al. Guidelines for the initial biopsy diagnosis of suspected chronic idiopathic inflammatory bowel disease: the British Society of Gastroenterology Initiative. J Clin Pathol 1997;50:93-105.

45. Dundas SA, Dutton J, Skipworth P. Reliability of rectal biopsy in distinguishing between chronic inflammatory bowel disease and acute self-limiting colitis. Histopathology 1997;31:60-66.

46. Tanaka M, Saito H, Kusumi T, et al. Spatial distribution and histogenesis of colorectal Paneth cell metaplasia in idiopathic inflammatory bowel disease. J Gastroenterol Hepatol 2001;16:1353-1359.

47. Nostrant TT, Kumar NB, Appelman HD. Histopathology differentiates acute self-limited colitis from ulcerative colitis. Gastroenterology 1987;92:318-328.

48. Schmitz-Moormann P, Himmelmann GW. Does quantitative histology of rectal biopsy improve the differential diagnosis of Crohn's disease and ulcerative colitis in adults? Pathol Res Pract 1988;183:481-488.

49. DeRoche TC, Xiao SY, Liu X. Histological evaluation in ulcerative colitis. Gastroenterol Rep (Oxf) 2014;2:178-192.

50. Tanaka M, Riddell RH, Saito H, Soma Y, Hidaka H, Kudo H. Morphologic criteria applicable to biopsy specimens for effective distinction of inflammatory bowel disease from other forms of colitis and of Crohn's disease from ulcerative colitis. Scand J Gastroenterol 1999;34:55-67.

51. Goldstein N, Dulai M. Contemporary morphologic definition of backwash ileitis in ulcerative colitis and features that distinguish it from Crohn disease. Am J Clin Pathol 2006;126:365376.

52. Kim B, Barnett JL, Kleer CG, Appelman HD. Endoscopic and histological patchiness in treated ulcerative colitis. Am J Gastroenterol 1999;94:3258-3262.
53. Kleer CG, Appelman HD. Ulcerative colitis: patterns of involvement in colorectal biopsies and changes with time. Am J Surg Pathol 1998;22:983-989.

54. Bernstein CN, Shanahan F, Anton PA, Weinstein WM. Patchiness of mucosal inflammation in treated ulcerative colitis: a prospective study. Gastrointest Endosc 1995;42:232-237.

55. Ott JJ, Stevens GA, Groeger J, Wiersma ST. Global epidemiology of hepatitis B virus infection: new estimates of age-specific HBsAg seroprevalence and endemicity. Vaccine 2012;30:22122219.

56. Cheon JH. Understanding the complications of anti-tumor necrosis factor therapy in East Asian patients with inflammatory bowel disease. J Gastroenterol Hepatol 2017;32:769-777.

57. Rahier JF, Magro F, Abreu C, et al. Second European evidencebased consensus on the prevention, diagnosis and management of opportunistic infections in inflammatory bowel disease. J Crohns Colitis 2014;8:443-468.

58. Loras C, Gisbert JP, Mínguez M, et al. Liver dysfunction related to hepatitis B and $\mathrm{C}$ in patients with inflammatory bowel disease treated with immunosuppressive therapy. Gut 2010;59:1340-1346.

59. Park SH, Yang SK, Lim YS, et al. Clinical courses of chronic hepatitis B virus infection and inflammatory bowel disease in patients with both diseases. Inflamm Bowel Dis 2012;18:20042010.

60. Altunöz ME, Senateş E, Yeşil A, Calhan T, Ovünç AO. Patients with inflammatory bowel disease have a lower response rate to $\mathrm{HBV}$ vaccination compared to controls. Dig Dis Sci 2012;57:1039-1044.

61. Gisbert JP, Menchén L, García-Sánchez V, Marín I, Villagrasa JR, Chaparro M. Comparison of the effectiveness of two protocols for vaccination (standard and double dosage) against hepatitis B virus in patients with inflammatory bowel disease. Aliment Pharmacol Ther 2012;35:1379-1385.

62. Weng MT, Wei SC, Lin CC, et al. Seminar report from the 2014 Taiwan Society of Inflammatory Bowel Disease (TSIBD) spring forum (May 24th, 2014): Crohn's disease versus intestinal tuberculosis infection. Intest Res 2015;13:6-10.

63. Horsburgh CR Jr, Rubin EJ. Clinical practice: latent tuberculosis infection in the United States. N Engl J Med 2011;364:14411448.

64. Tuberculosis diagnosis and treatment guidelines (version 5.1). Centers for Disease Control, R.O.C. (Taiwan) Web site. http:// www.cdc.gov.tw/professional/info.aspx?treeid=beac9c103df952 c4\&nowtreeid=6744c19c09435458\&tid=B02B73C3D6F15437. Updated December 17, 2015. Accessed March 3, 2017. 
65. Munkholm P, Michetti P, Probert CS, Elkjaer M, Marteau P. Best practice in the management of mild-to-moderately active ulcerative colitis and achieving maintenance of remission using mesalazine. Eur J Gastroenterol Hepatol 2010;22:912-916.

66. Cohen RD, Woseth DM, Thisted RA, Hanauer SB. A metaanalysis and overview of the literature on treatment options for left-sided ulcerative colitis and ulcerative proctitis. Am J Gastroenterol 2000;95:1263-1276.

67. Marshall JK, Irvine EJ. Rectal corticosteroids versus alternative treatments in ulcerative colitis: a meta-analysis. Gut 1997;40:775-781.

68. Safdi M, DeMicco M, Sninsky C, et al. A double-blind comparison of oral versus rectal mesalamine versus combination therapy in the treatment of distal ulcerative colitis. Am J Gastroenterol 1997;92:1867-1871.

69. Lewis JD, Gelfand JM, Troxel AB, et al. Immunosuppressant medications and mortality in inflammatory bowel disease. Am J Gastroenterol 2008;103:1428-1435.

70. Hoes JN, Jacobs JW, Verstappen SM, Bijlsma JW, Van der Heijden GJ. Adverse events of low- to medium-dose oral glucocorticoids in inflammatory diseases: a meta-analysis. Ann Rheum Dis 2009;68:1833-1838.

71. Lichtenstein GR. Budesonide multi-matrix for the treatment of patients with ulcerative colitis. Dig Dis Sci 2016;61:358-370.

72. Brunner M, Ziegler S, Di Stefano AF, et al. Gastrointestinal transit, release and plasma pharmacokinetics of a new oral budesonide formulation. Br J Clin Pharmacol 2006;61:31-38.

73. Sandborn WJ, Travis S, Moro L, et al. Once-daily budesonide MMX $^{\circ}$ extended-release tablets induce remission in patients with mild to moderate ulcerative colitis: results from the CORE I study. Gastroenterology 2012;143:1218-1226.

74. Travis SP, Danese S, Kupcinskas L, et al. Once-daily budesonide MMX in active, mild-to-moderate ulcerative colitis: results from the randomised CORE II study. Gut 2014;63:433-441.

75. Marteau P, Probert CS, Lindgren S, et al. Combined oral and enema treatment with Pentasa (mesalazine) is superior to oral therapy alone in patients with extensive mild/moderate active ulcerative colitis: a randomised, double blind, placebo controlled study. Gut 2005;54:960-965.

76. Kamm MA, Sandborn WJ, Gassull M, et al. Once-daily, highconcentration MMX mesalamine in active ulcerative colitis. Gastroenterology 2007;132:66-75.

77. Kruis W, Kiudelis G, Rácz I, et al. Once daily versus three times daily mesalazine granules in active ulcerative colitis: a doubleblind, double-dummy, randomised, non-inferiority trial. Gut 2009;58:233-240.
78. Sandborn WJ, Kamm MA, Lichtenstein GR, Lyne A, Butler T, Joseph RE. MMX Multi Matrix System mesalazine for the induction of remission in patients with mild-to-moderate ulcerative colitis: a combined analysis of two randomized, doubleblind, placebo-controlled trials. Aliment Pharmacol Ther 2007;26:205-215.

79. Truelove SC, Jewell DP. Intensive intravenous regimen for severe attacks of ulcerative colitis. Lancet 1974;1:1067-1070.

80. Turner D, Walsh CM, Steinhart AH, Griffiths AM. Response to corticosteroids in severe ulcerative colitis: a systematic review of the literature and a meta-regression. Clin Gastroenterol Hepatol 2007;5:103-110.

81. Laharie D, Bourreille A, Branche J, et al. Ciclosporin versus infliximab in patients with severe ulcerative colitis refractory to intravenous steroids: a parallel, open-label randomised controlled trial. Lancet 2012;380:1909-1915.

82. Lennard-Jones JE, Ritchie JK, Hilder W, Spicer CC. Assessment of severity in colitis: a preliminary study. Gut 1975;16:579-584.

83. Lindgren SC, Flood LM, Kilander AF, Löfberg R, Persson TB, Sjödahl RI. Early predictors of glucocorticosteroid treatment failure in severe and moderately severe attacks of ulcerative colitis. Eur J Gastroenterol Hepatol 1998;10:831-835.

84. Benazzato L, D'Incà R, Grigoletto $F$, et al. Prognosis of severe attacks in ulcerative colitis: effect of intensive medical treatment. Dig Liver Dis 2004;36:461-466.

85. Chew CN, Nolan DJ, Jewell DP. Small bowel gas in severe ulcerative colitis. Gut 1991;32:1535-1537.

86. Almer S, Bodemar G, Franzén L, Lindström E, Nyström P, Ström M. Use of air enema radiography to assess depth of ulceration during acute attacks of ulcerative colitis. Lancet 1996;347:1731-1735.

87. Randall J, Singh B, Warren BF, Travis SP, Mortensen NJ, George BD. Delayed surgery for acute severe colitis is associated with increased risk of postoperative complications. Br J Surg 2010;97:404-409.

88. Wang Y, Parker CE, Feagan BG, MacDonald JK. Oral 5-aminosalicylic acid for maintenance of remission in ulcerative colitis. Cochrane Database Syst Rev 2016;(5):CD000544. doi: 10.1002/14651858.CD000544.pub4.

89. Gionchetti P, Rizzello F, Venturi A, et al. Comparison of oral with rectal mesalazine in the treatment of ulcerative proctitis. Dis Colon Rectum 1998;41:93-97.

90. Marshall JK, Irvine EJ. Putting rectal 5-aminosalicylic acid in its place: the role in distal ulcerative colitis. Am J Gastroenterol 2000;95:1628-1636.

91. Prantera C, Marconi S. Glucocorticosteroids in the treatment of inflammatory bowel disease and approaches to minimizing systemic activity. Therap Adv Gastroenterol 2013;6:137-156. 
92. Timmer A, McDonald JW, Macdonald JK. Azathioprine and 6-mercaptopurine for maintenance of remission in ulcerative colitis. Cochrane Database Syst Rev 2007;(1):CD000478. doi: 10.1002/14651858.CD000478.pub2.

93. Ardizzone S, Maconi G, Russo A, Imbesi V, Colombo E, Bianchi Porro G. Randomised controlled trial of azathioprine and 5-aminosalicylic acid for treatment of steroid dependent ulcerative colitis. Gut 2006;55:47-53.

94. Fernández-Bañares F, Bertrán X, Esteve-Comas M, et al. Azathioprine is useful in maintaining long-term remission induced by intravenous cyclosporine in steroid-refractory severe ulcerative colitis. Am J Gastroenterol 1996;91:2498-2499.

95. Moskovitz DN, Van Assche G, Maenhout B, et al. Incidence of colectomy during long-term follow-up after cyclosporine-induced remission of severe ulcerative colitis. Clin Gastroenterol Hepatol 2006;4:760-765.

96. Rutgeerts P, Sandborn WJ, Feagan BG, et al. Infliximab for induction and maintenance therapy for ulcerative colitis. N Engl J Med 2005;353:2462-2476.

97. Sandborn WJ, van Assche G, Reinisch W, et al. Adalimumab induces and maintains clinical remission in patients with moderate-to-severe ulcerative colitis. Gastroenterology 2012;142:257-265.e3.

98. Sandborn WJ, Feagan BG, Marano C, et al. Subcutaneous golimumab maintains clinical response in patients with moderate-to-severe ulcerative colitis. Gastroenterology 2014;146:96109.

99. Monterubbianesi R, Daperno M, Armuzzi A, et al. Infliximab for severe ulcerative colitis: short-term and one year outcome of three dose regimen: an Italian multicentre open-label study. Gastroenterology 2010;138:S685.

100. Venu M, Naik AS, Ananthakrishnan AN, et al. Early infliximab infusion in hospitalized severe UC patients: one year outcome. Gastroenterology 2009;136 (Suppl 1):A201.

101. Feagan BG, Rutgeerts P, Sands BE, et al. Vedolizumab as induction and maintenance therapy for ulcerative colitis. N Engl J Med 2013;369:699-710.

102. Keane J, Gershon S, Wise RP, et al. Tuberculosis associated with infliximab, a tumor necrosis factor alpha-neutralizing agent. N Engl J Med 2001;345:1098-1104.

103. Toruner M, Loftus EV Jr, Harmsen WS, et al. Risk factors for opportunistic infections in patients with inflammatory bowel disease. Gastroenterology 2008;134:929-936.

104. Mackey AC, Green L, Liang LC, Dinndorf P, Avigan M. Hepatosplenic $\mathrm{T}$ cell lymphoma associated with infliximab use in young patients treated for inflammatory bowel disease. J Pediatr Gastroenterol Nutr 2007;44:265-267.
105. Kotlyar DS, Osterman MT, Diamond RH, et al. A systematic review of factors that contribute to hepatosplenic T-cell lymphoma in patients with inflammatory bowel disease. Clin Gastroenterol Hepatol 2011;9:36-41.

106. Froslie KF, Jahnsen J, Moum BA, Vatn MH; IBSEN Group. Mucosal healing in inflammatory bowel disease: results from a Norwegian population-based cohort. Gastroenterology 2007;133:412-422.

107. Wright R, Truelove SR. Serial rectal biopsy in ulcerative colitis during the course of a controlled therapeutic trial of various diets. Am J Dig Dis 1966;11:847-857.

108. Meucci G, Fasoli R, Saibeni S. Prognostic significance of endoscopy remission in patients with active ulcerative colitis treated with oral and topical mesalazine: preliminary results of a prospective, multicenter study. Gastroenterology 2006;130.

109. Rutter MD, Saunders BP, Wilkinson KH, et al. Cancer surveillance in longstanding ulcerative colitis: endoscopic appearances help predict cancer risk. Gut 2004;53:1813-1816.

110. Appropriate use of gastrointestinal endoscopy. American Society for Gastrointestinal Endoscopy. Gastrointest Endosc 2000;52:831-837.

111. Leighton JA, Shen B, Baron TH, et al. ASGE guideline: endoscopy in the diagnosis and treatment of inflammatory bowel disease. Gastrointest Endosc 2006;63:558-565.

112. Bjarnason I, Sherwood R. Fecal calprotectin: a significant step in the noninvasive assessment of intestinal inflammation. J Pediatr Gastroenterol Nutr 2001;33:11-13.

113. Summerton CB, Longlands MG, Wiener K, Shreeve DR. Faecal calprotectin: a marker of inflammation throughout the intestinal tract. Eur J Gastroenterol Hepatol 2002;14:841-845.

114. Lin WC, Wong JM, Tung CC, et al. Fecal calprotectin correlated with endoscopic remission for Asian inflammatory bowel disease patients. World J Gastroenterol 2015;21:13566-13573.

115. Limburg PJ, Ahlquist DA, Sandborn WJ, et al. Fecal calprotectin levels predict colorectal inflammation among patients with chronic diarrhea referred for colonoscopy. Am J Gastroenterol 2000;95:2831-2837.

116. Tibble JA, Sigthorsson G, Bridger S, Fagerhol MK, Bjarnason I. Surrogate markers of intestinal inflammation are predictive of relapse in patients with inflammatory bowel disease. Gastroenterology 2000;119:15-22.

117. Costa F, Mumolo MG, Ceccarelli L, et al. Calprotectin is a stronger predictive marker of relapse in ulcerative colitis than in Crohn's disease. Gut 2005;54:364-368.

118. Aadland E, Fagerhol MK. Faecal calprotectin: a marker of inflammation throughout the intestinal tract. Eur J Gastroenterol Hepatol 2002;14:823-825. 
119. Røseth AG, Aadland E, Grzyb K. Normalization of faecal calprotectin: a predictor of mucosal healing in patients with inflammatory bowel disease. Scand J Gastroenterol 2004;39:1017-1020.

120. Konikoff MR, Denson LA. Role of fecal calprotectin as a biomarker of intestinal inflammation in inflammatory bowel disease. Inflamm Bowel Dis 2006;12:524-534.

121. Schoepfer AM, Trummler M, Seeholzer P. Calprotectin helps to distinguish between an acute IBD episode and symptoms related to IBS. Inflamm Bowel Dis 2008;14:1432-1439.

122. Rodgers AD, Cummins AG. CRP correlates with clinical score in ulcerative colitis but not in Crohn's disease. Dig Dis Sci 2007;52:2063-2068.

123. Sachar DB, Smith H, Chan S, Cohen LB, Lichtiger S, Messer J. Erythrocytic sedimentation rate as a measure of clinical activity in inflammatory bowel disease. J Clin Gastroenterol 1986;8:647-650.

124. Prantera C, Davoli M, Lorenzetti R, et al. Clinical and laboratory indicators of extent of ulcerative colitis: serum C-reactive protein helps the most. J Clin Gastroenterol 1988;10:41-45.

125. Solem CA, Loftus EV Jr, Tremaine WJ, Harmsen WS, Zinsmeister AR, Sandborn WJ. Correlation of C-reactive protein with clinical, endoscopic, histologic, and radiographic activity in inflammatory bowel disease. Inflamm Bowel Dis 2005;11:707712.

126. Murdoch T, O’Donnell S, Silverberg MS, Panaccione R. Biomarkers as potential treatment targets in inflammatory bowel disease: a systematic review. Can J Gastroenterol Hepatol 2015;29:203-208.

127. Schneeweiss S, Korzenik J, Solomon DH, Canning C, Lee J, Bressler B. Infliximab and other immunomodulating drugs in patients with inflammatory bowel disease and the risk of serious bacterial infections. Aliment Pharmacol Ther 2009;30:253264.

128. Hsu J, Abad C, Dinh M, Safdar N. Prevention of endemic healthcare-associated Clostridium difficile infection: reviewing the evidence. Am J Gastroenterol 2010;105:2327-2339.

129. Johal SS, Hammond J, Solomon K, James PD, Mahida YR. Clostridium difficile associated diarrhoea in hospitalised patients: onset in the community and hospital and role of flexible sigmoidoscopy. Gut 2004;53:673-677.

130. Kandiel A, Lashner B. Cytomegalovirus colitis complicating inflammatory bowel disease. Am J Gastroenterol 2006;101:28572865.

131. Nakase H, Chiba T. TNF-alpha is an important pathogenic factor contributing to reactivation of cytomegalovirus in inflamed mucosa of colon in patients with ulcerative colitis: lesson from clinical experience. Inflamm Bowel Dis 2010;16:550-551.
132. Riley SA, Mani V, Goodman MJ, Dutt S, Herd ME. Microscopic activity in ulcerative colitis: what does it mean? Gut 1991;32:174-178.

133. Geboes K, Riddell R, Ost A, Jensfelt B, Persson T, Löfberg R. A reproducible grading scale for histological assessment of inflammation in ulcerative colitis. Gut 2000;47:404-409.

134. Marchal-Bressenot A, Salleron J, Boulagnon-Rombi C, et al. Development and validation of the Nancy histological index for UC. Gut 2017;66:43-49.

135. Mosli MH, Feagan BG, Zou G, et al. Development and validation of a histological index for UC. Gut 2017;66:50-58.

136. Øresland T, Bemelman WA, Sampietro GM, et al. European evidence based consensus on surgery for ulcerative colitis. J Crohns Colitis 2015;9:4-25.

137. Fazio VW, Kiran RP, Remzi FH, et al. Ileal pouch anal anastomosis: analysis of outcome and quality of life in 3707 patients. Ann Surg 2013;257:679-685.

138. Ording Olsen K, Juul S, Berndtsson I, Øresland T, Laurberg S. Ulcerative colitis: female fecundity before diagnosis, during disease, and after surgery compared with a population sample. Gastroenterology 2002;122:15-19.

139. Rajaratnam SG, Eglinton TW, Hider P, Fearnhead NS. Impact of ileal pouch-anal anastomosis on female fertility: meta-analysis and systematic review. Int J Colorectal Dis 2011;26:13651374.

140. Waljee A, Waljee J, Morris AM, Higgins PD. Threefold increased risk of infertility: a meta-analysis of infertility after ileal pouch anal anastomosis in ulcerative colitis. Gut 2006;55:15751580.

141. Thomas DM, Filipe MI, Smedley FH. Dysplasia and carcinoma in the rectal stump of total colitics who have undergone colectomy and ileo-rectal anastomosis. Histopathology 1989;14:289-298.

142. Williamson ME, Lewis WG, Sagar PM, Holdsworth PJ, Johnston D. One-stage restorative proctocolectomy without temporary ileostomy for ulcerative colitis: a note of caution. Dis Colon Rectum 1997;40:1019-1022.

143. Van Assche G, Dignass A, Bokemeyer B, et al. Second European evidence-based consensus on the diagnosis and management of ulcerative colitis part 3: special situations. J Crohns Colitis 2013;7:1-33.

144. Sandborn WJ. Pouchitis following ileal pouch-anal anastomosis: definition, pathogenesis, and treatment. Gastroenterology 1994;107:1856-1860.

145. Shen B, Lashner BA. Diagnosis and treatment of pouchitis. Gastroenterol Hepatol (N Y) 2008;4:355-361. 
146. Shen B, Achkar JP, Lashner BA, et al. Endoscopic and histologic evaluation together with symptom assessment are required to diagnose pouchitis. Gastroenterology 2001;121:261-267.

147. Chiang CJ, Chen YC, Chen CJ, You SL, Lai MS; Taiwan Cancer Registry Task Force. Cancer trends in Taiwan. Jpn J Clin Oncol 2010;40:897-904.

148. Eaden JA, Abrams KR, Mayberry JF. The risk of colorectal cancer in ulcerative colitis: a meta-analysis. Gut 2001;48:526-535.

149. Nuako KW, Ahlquist DA, Mahoney DW, Schaid DJ, Siems DM, Lindor NM. Familial predisposition for colorectal cancer in chronic ulcerative colitis: a case-control study. Gastroenterology 1998;115:1079-1083.

150. Shetty K, Rybicki L, Brzezinski A, Carey WD, Lashner BA. The risk for cancer or dysplasia in ulcerative colitis patients with primary sclerosing cholangitis. Am J Gastroenterol 1999;94:1643-1649.

151. Giardiello FM, Gurbuz AK, Bayless TM, Goodman SN, Yardley JH. Colorectal cancer in ulcerative colitis: survival in patients with and without colorectal cancer symptoms. Inflamm Bowel Dis 1996;2:6-10.
152. Kiesslich R, Neurath MF. Advanced endoscopy imaging in inflammatory bowel diseases. Gastrointest Endosc 2017;85:496508.

153. Kappelman MD, Farkas DK, Long MD, et al. Risk of cancer in patients with inflammatory bowel diseases: a nationwide population-based cohort study with 30 years of follow-up evaluation. Clin Gastroenterol Hepatol 2014;12:265-273.

154. Cullen SN, Chapman RW. The medical management of primary sclerosing cholangitis. Semin Liver Dis 2006;26:52-61.

155. Huai JP, Ding J, Ye XH, Chen YP. Inflammatory bowel disease and risk of cholangiocarcinoma: evidence from a metaanalysis of population-based studies. Asian Pac J Cancer Prev 2014;15:3477-3482.

156. Kariv R, Remzi FH, Lian L, et al. Preoperative colorectal neoplasia increases risk for pouch neoplasia in patients with restorative proctocolectomy. Gastroenterology 2010;139:806812. 